\title{
Studies on Culture and Creative economics in Belgium (Brussels, Flanders and Wallonia)
}

\author{
Elisabetta Lazzaro \\ Professor of Creative Economy, HKU Academy of The Arts Utrecht, Utrecht, Netherlands \\ elisabetta.lazzaro@hku.nl
}

\begin{abstract}
In recent decades, new forces, such as China, Russia and Brazil, have emerged in the international contemporary art market as part of the creative economy. At the same time the art market is becoming more visible globally, with the same art galleries and the same artists can be exhibited in different art exhibitions. For example, between 2008 and 2015 creative economic growth in Brussels has increased rapidly, from 37\% in 2007 to $75 \%$ by 2015.

In this paper we propose answering questions such as: How is the opportunity given by a creative entity to a particular creative person from a particular country represented in another country like Belgium at the international level? Can we observe the trends of art and the creative economy in the last decade? What is the underlying? Implications? By applying a cluster analysis, we map the creative economy market and look for trends according to the level of diversity in terms of art and artists or designers represented by exhibitions at international and national levels in Europe. To develop this analysis, we have established partnerships with Artfacts.net to get unique data about exhibitions in Europe.
\end{abstract}

Keywords Creative Economy, Europe, Global Trend

\section{Introduction}

Previous studies on Culture and Creative economics in Belgium rarely involve Brussels separately, except Lazzaro and Lowies (2014). There has been no research focusing on this situation in the capital and analyzed in detail. But the situation in Brussels is different from other parts of Belgium: Compared to other parts of the country, the city is much more urban and far more cosmopolitan. As the regional capital, it is characterized by a complex network of overlapping jurisdictions and is also home to the headquarters of public and private media organizations. It has good consequences for the size and composition of the cultural and creative economy in this city.

The purpose of this study is to analysis information that is related to the making of precise picture of the economic situation by utilizing all available data. We focus on clear economic indicators, which then can be easily compared geographically and in time. Thus, we also discuss broadly the benefits of culture and creativity in encouraging innova- tion and urban development.

\section{Methodology}

Our methodology can be summarized as follows:

1. Definition of Cultural and Creative Economy, based on the classification of economic sector.

2. Grouping the above mentioned creative economic clusters into two alternative subdivisions, sectors and circles:

- The first is subdivision into 10 sectors.

This is an Art Performance; Libraries, Archives and Museums; Photography; Art and Antiques Store; Audio visual; Print media; Mode; Advertising; Architecture and Design.

- The second divides the creative economy into a circle:

Art Core, Creative Core, Art Support and Creative Support

3. Application of this definition to various data sets: 
- Data input based on cluster level and chronologically, if possible.

- Inference to creative economic content in the form of aggregate data using estimates from the more disaggregated.

The above methodology applies to estimates of the following key measures: Type of enterprise in the sector of creative economy, turnover, added value and type of activity in the creative economy.

The study aims to explain the creative economy in Brussels and its development over time, but also into its composition, labor features as well as its geographic distribution. In recognition of the characteristics of several sub-sectors, particularly those of a cultural nature, the analysis will provide a key aggregate for the overall culture and creative economy as well as detailed investigations of the dynamic sub-sectoral when deemed relevant to previous studies of the creative economy undertaken by Flanders (Schrauwen et al., 2014, Guiette et al., 2011) and Wallonia (Idea Consult, 2014, and particularly Lazzaro and Lowies, 2014) have included Brussels for various areas but not aimed specifically to describe the situation in the capital region.

Politically, the region is governed by a linguistically arranged system that guarantees its similarities to France and the Netherlands. Linguistically speaking, the primary language spoken at home is French (38\%) and only 5\% of the number of pure Brussels-speaking Brussels (BRIO Brussels Informatie, Documentatie en Onderzoekscentrum, 2013).

\section{Definition of the Creative Economy}

The definition of a creative economy varies in literature and currently no single definition is widely accepted, although there is considerable overlap between the studies.

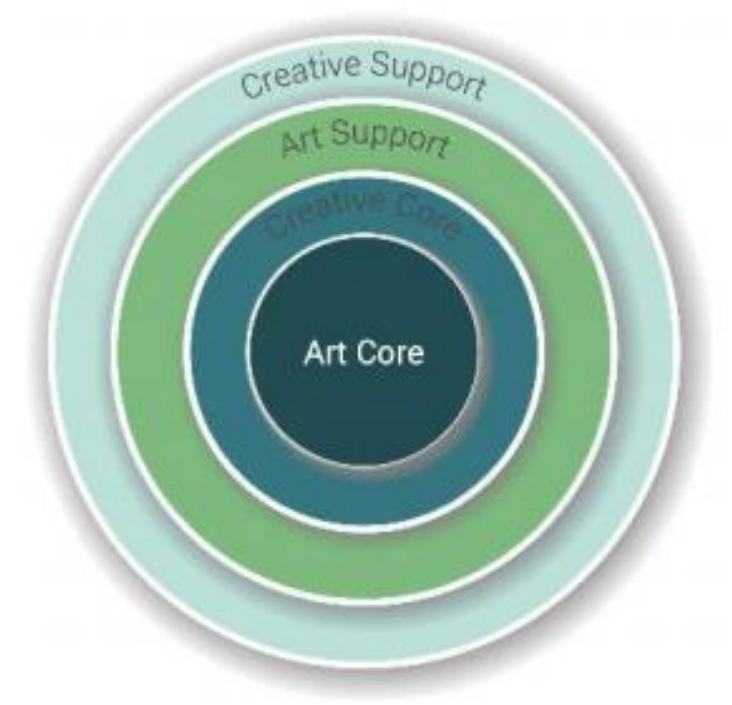

Figure 1. Visualization between Art and Creative Economy

Description The concentric circle model used here is inspired by Throsby (2008) and has been customized. The creative economy is divided into four 'circles', where the center of the circle, the Art Core, is meant to have the highest creativity in cultural content. This creative content then declines as it moves into the outer circle, which represents more peripheral creative activity, here it is labeled as Art Support and Creative Support.

As in Lazzaro and Lowies (2014) the value of cultural and creative goods is limited to the top, excluding manufacturing, while also including wholesale and retail. The purpose of this option is to limit the level of analysis while maintaining consistency and avoiding distortion in Measurement creation, assembly, and post-production, distribution and retail including for all creative goods. It should be noted that the typical value chain is short, where many cultural or creative companies provide services and use multiple inputs other than office space and labor, where more value chains exist and are captured by a classification system. As in mode, sections have some limitations related to their use.

\section{Classification of economic activities}

The category standardization does not fully understand the differences between activities, making it difficult to know precisely what activities a particular company does, especially for a company doing some activities and for service providers. More worrying that creative economy-based jobs fail to be understood by the public sector. 
Similar problems can be observed for nonprofits. We still choose to display our analysis based on the creative industry classification to allow for comparison of our results with previous research and to utilize existing official statistics, whereby the more creative ones are closer to the concentric circle model center.

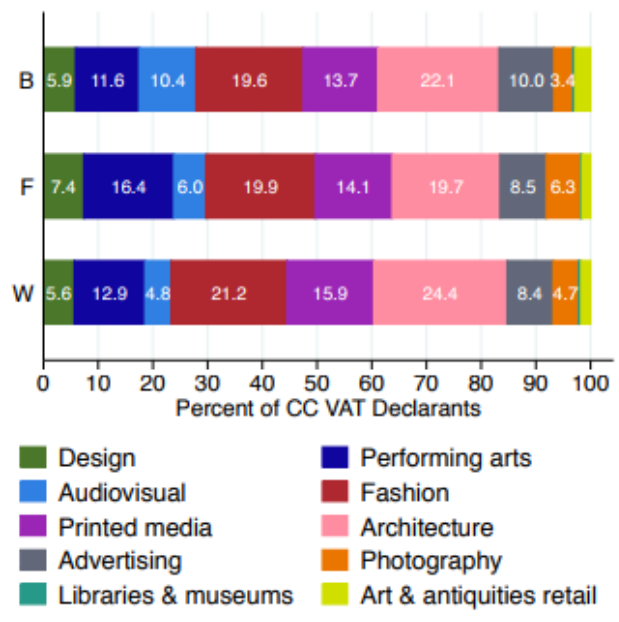

Figure 2. VAT Declarants based on Sectors

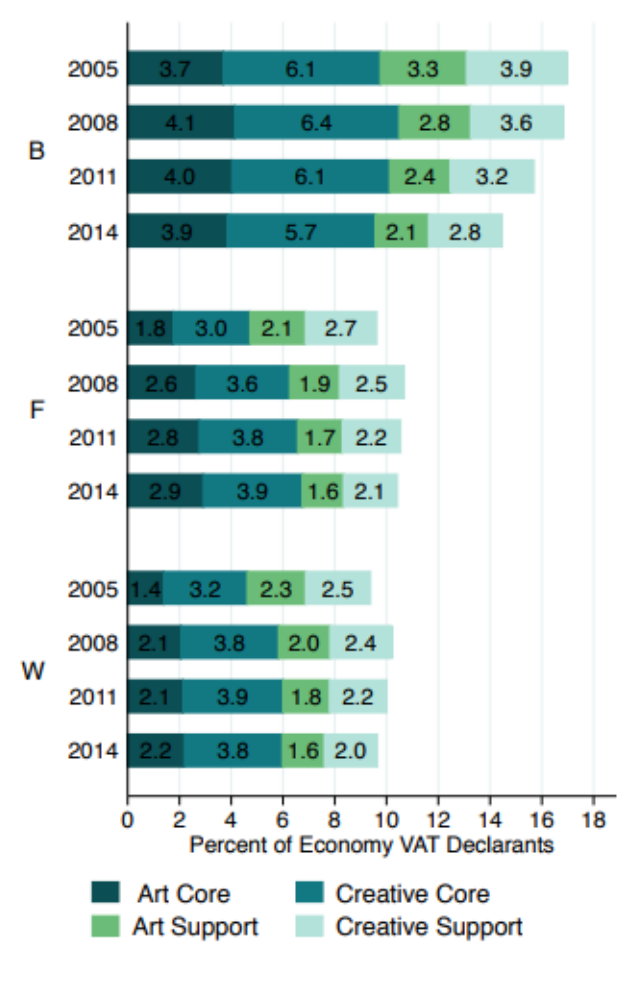

Figure 3. Creative Sector Economy based on Circle
Differences between regions can be recognized in this graph. Brussels has a larger share of Audiovisual Media and Advertising Entities.

But if this distinction seems marginal, it is so because the more important difference between Brussels and the rest of the region is related to things not caught here: Composition of activities in group and firm size.
In particular, Performing Arts entities are concentrated in partially overlapping areas (west and south) called "croissant pauvre" that includes the Molenbeek neighborhood Historique (where fashion, retail possibilities, is also important); Dansaert and Anneessens; Marolles and the northern part of Anderlecht, Saint-Gilles. Low-income neighborhood, Flagey-Malibran in Ixelles, showing the high performing arts density.

Looking at job data can complement our view of culture and creativity in the economy. It is important to note that this analysis does not take into account changes the definition given above, but rather intended to be given an additional perspective regarding the term 'Culture and the Creative Economy' which will continue to refer to sector classification. The attractiveness of your economic creative conception includes all workers in the field of creative economic work in the idea that creative work is done across all economic activities rather than concentrated in sectors whose main activities can be characterized as Culture or Creative. Since software developers and web designers are among these creative economic jobs, and because actors are looking for jobs in many different sectors, we also suspect the number of creative professionals working outside the creative economy of the economy can continue to grow. 


\section{Conclusions}

This study has measured and mapped Culture and Creative Economy in the Brussels region in various dimensions. Using standard sectoral delineation approaches, we show such things as: a larger creative economy takes place in Brussels than in other parts of Belgium.

This may be partly due to urban character, this is also reflected in the manner in which the creative economic composition of Brussels is different from its composition in Flanders and Wallonia. A much larger role is played in Brussels by the advertising sector and the audiovisual sector because of this city

It's a big advertising and broadcasting company. Judging from time to time, the economic part represented by the creative economy has declined in the last decade. The cause is not all clear and all sectors of the creative economy are affected to some degree but there is a significant difference. Some, such as print media have shrunk very strongly and spilled a large number of workers in this sector almost certainly associated with ongoing digitalization. Others, such as those included in what we call Art Core, have shown themselves to be durable even in times of crisis.

\section{Bibliography}

[a] Guiette, A., Jacobs, S., Schramme, A., Vandenbempt, K., DC Flanders, and Antwerp Management School (2011). Creative Industries in Flanders: Mapping and economic analysis.

[b] Higgs, P. L., Cunningham, S. D., and Bakhshi, H. (2008). Beyond the creative industries: Mapping the creative economy in the United Kingdom.

[c] Idea Consult (2014). Analyse des liens entre l'industrie wallonne, les services à haute intensité de connaissances et les industries créatives et culturelles, dans une perspective de chaînes de valeur. Brussels.

[d] Lazzaro, E. (2017). Cultural and Creative Entrepreneurs. In Mickov, B. and Doyle, J. E., editors, Culture, Innovation and the Economy, chapter 7. Routledge, London.

[e] Lazzaro, E. and Lowies, J.-G. (2014). Le poids économique des Industries culturelles et créatives en Wallonie et à Bruxelles. Institut wallon de l'évaluation, de la prospective et de la statistique (IWEPS).

[f] Lee, N. and Rodríguez-Pose, A. (2013). Creativity, cities and innovation: Evidence from UK SMEs. Nesta, London. [g] Loose, M. and Lamberts, M. (2006). Kunst en kunde. Aanzet tot een monitoring instrument voor de artistieke sector. Hoger Instituut voor de Arbeid (K.U.Leuven).

[h] Mikić, H. and Unesco Institute for Statistics (2012). Measuring the Economic Contribution of Cultural Industries: A Review and Assessment of Current Methodological Approaches. 2009 UNESCO framework for cultural statistics handbook. UNESCO Institute for Statistics, Paris. 